\title{
Comparison of Nutation Theories
}

\author{
Dennis D. McCarthy \\ U.S. Naval Observatory, Washington, DC 20392, USA
}

\begin{abstract}
Analyses of residuals between VLBI observations and combinations of nutation series show that the MHB 2000 nonrigid-Earth nutation model applied to the REN 2000 rigid-Earth model results in the best fit, and that amplitudes of any possible periodic terms remaining in the observed corrections to the MHB2000 theory could be expected to be less than 0.1 mas.
\end{abstract}

\section{Introduction}

The IAU/IUGG Working Group on Nonrigid-Earth Nutation in its report (Dehant 2000) describes both rigid-Earth and non rigid-Earth nutation theories that have been developed in recent years. To evaluate these theories for possible acceptance by the international community it is necessary to compare them with observations. This paper presents the results of the comparison of combinations of rigid and nonrigid-Earth nutation theories to recent high-precision astronomical observations.

\section{Observations}

Observations of corrections to the IAU Precession/Nutation Theory are provided by very long baseline interferometry (VLBI). For the purpose of this comparison the series derived by the National Earth Orientation Service (NEOS) was used. The series of data begins with MJD 44090 (1979) and ends with MJD 51618 (2000). Some VLBI observing sessions that were designed primarily to determine motions of observing sites produced poor results in precession/nutation. The results from these sessions were not used in this comparison.

\section{Nutation Theories}

The theories used in the comparison are (1) MHB2000 (Mathews et al. 2000, see also Mathews 2000) applied to the REN 2000 rigid-Earth theory (Souchay et al. 1999), (2) MHB2000 applied to the SMART97 rigid-Earth theory (Bretagnon et al. 1997, 1998), (3) MHB2000 applied to RDAN97 rigid-Earth theory (Roosbeek and Dehant 1998), (4) SF2000 (Shirai and Fukushima 2000a,b), (5) FG2000 (Getino and Ferrándiz 2000). MHB2000 provides a transfer function to be applied to a rigid-Earth theory of nutation to derive a nonrigid-Earth theory. The FG2000 model uses a global Hamiltonian approach for 106 waves fit to 


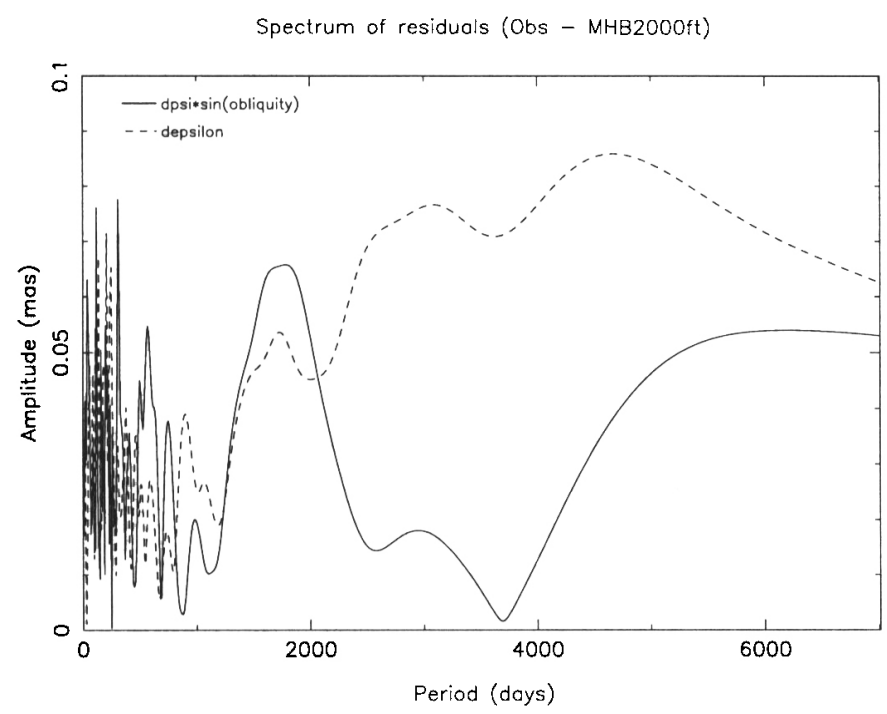

Figure 1.

VLBI data, and the SF2000 is an empirical model, based on a resonance formula fit to VLBI observations.

\section{Comparison of Theories with Observations}

In comparing theories with observations a time series of residuals was formed by subtracting the theoretical corrections from the observations. Each of these time series was then fit with a straight line to evaluate the rate and bias at the epoch of J2000.0. These values and the rms of each fit is shown in Table 1 for both the obliquity and the longitude of the ascending node of the ecliptic.

\section{Discussion}

The table shows that the MHB2000 theory applied to the REN 2000 rigid-Earth theory represents a marginal improvement over any of the others. All differences are statistically significant at the $99 \%$ level. Figure 1 shows an amplitude spectrum of the residual differences between the observations and the MHB2000 theory applied to REN 2000. Amplitudes of any possible periodic terms appear from this figure to be under 0.1 mas.

\section{Conclusion}

From this analysis of the residuals between the VLBI observations and the combinations of nutation theories, it appears that the MHB 2000 nonrigid-Earth nutation model applied to the REN 2000 Rigid-Earth model results in the best fit and that amplitudes of any possible periodic terms remaining in the observed corrections to this theory could be expected to be less than 0.1 mas. 


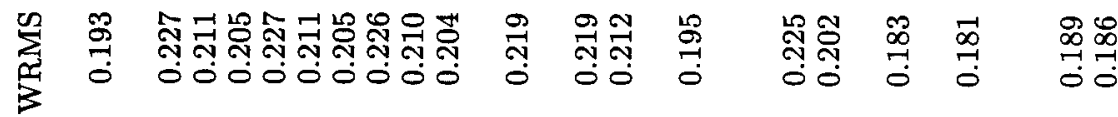

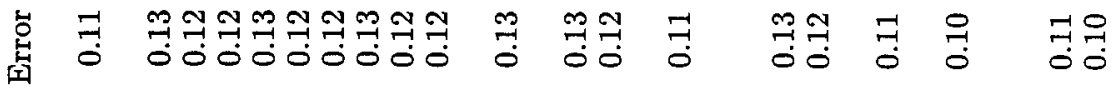

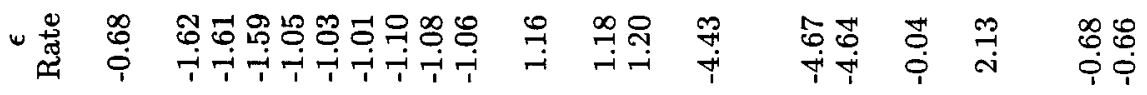

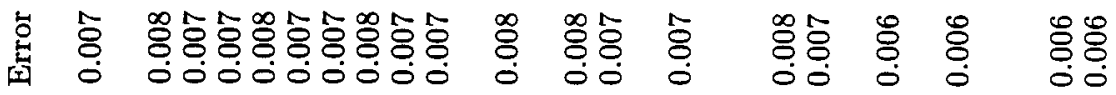

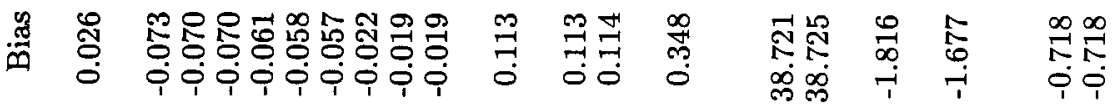

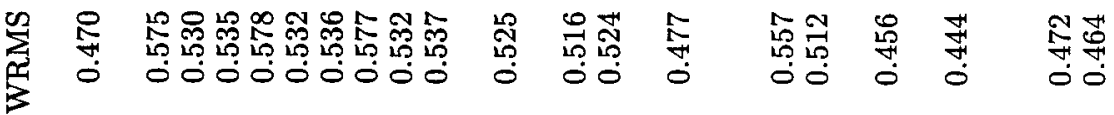

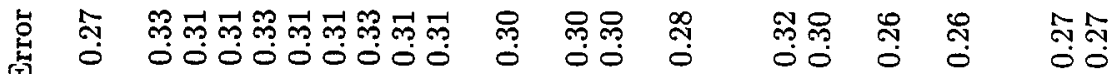

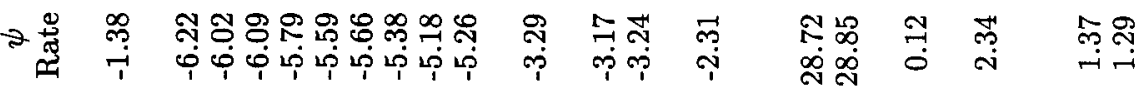

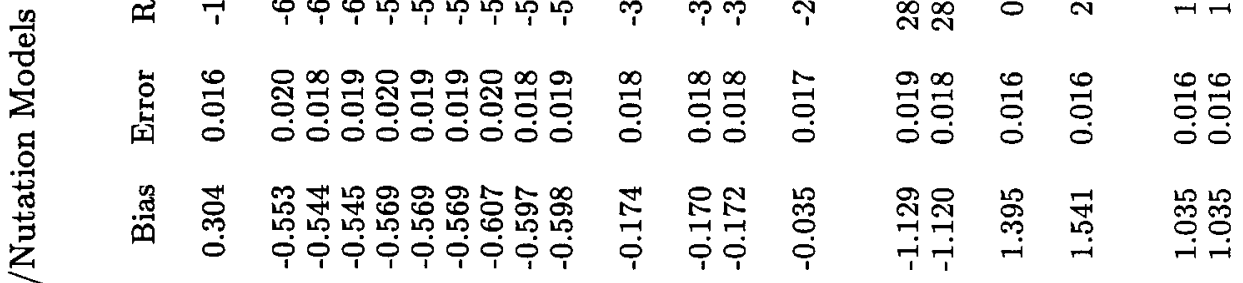

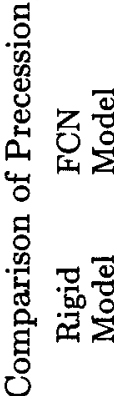

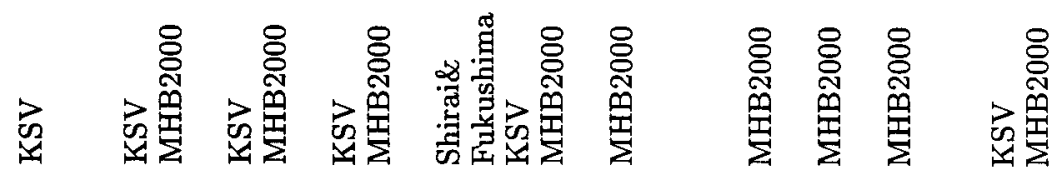

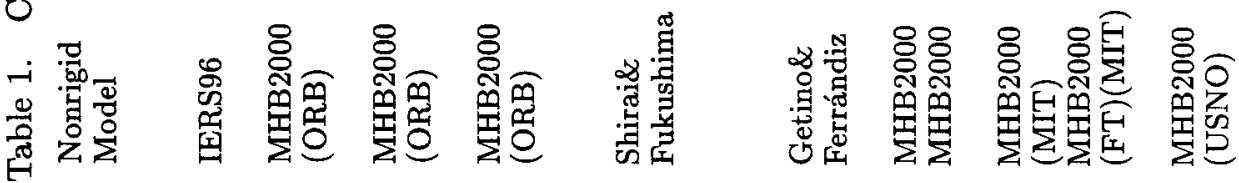




\section{References}

Bretagnon, P., Rocher, P., \& Simon, J.-L. 1997, A\&A, 319, 305

Bretagnon, P., Francou, G., Rocher, P., \& Simon, J.-L. 1998, A\&A, 329, 329

Dehant, V. 2000, in Proc. of IAU Coll. 180, eds. K. Johnston, D. McCarthy, B. Luzum \& G. Kaplan, Washington, USA, 201

Getino, J. \& Ferrándiz, J. M. 2000, in Proc. of IAU Coll. 180, eds. K. Johnston, D. McCarthy, B. Luzum \& G. Kaplan, Washington, USA, 236

Mathews, P.M. 2000, in Proc. of IAU Coll. 180, eds. K. Johnston, D. McCarthy, B. Luzum and G. Kaplan, Washington, USA, 212

Mathews, P. M., Herring, T., \& Buffett, B. 2000, "Modeling of nutation-precession: new nutation series for nonrigid Earth, and insights into the Earth's interior", J. Geophys. Res., submitted

Roosbeek, F. \& Dehant, V. 1998, Celest. Mech., 70, 215

Shirai T. \& Fukushima T. 2000a, "Improvement of non-rigid Earth nutation theory by adding a model free core nutation term", Astron. J., submitted, also in Proc. of IAU Coll. 180, eds. K. Johnston, D. McCarthy, B. Luzum \& G. Kaplan, Washington, USA, 223

Shirai T. and Fukushima T. 2000b, "Numerical convolution in the time domain and its apllication to the non-rigid Earth nutation theory", Astron. J., in press

Souchay, J. \& Kinoshita, H. 1996, A\&A, 312, 1017

Souchay, J. \& Kinoshita, H. 1997, A\&A, 318, 639

Souchay, J., Loysel, B., Kinoshita, H. \& Folgueira, M. 1999, A\&AS, 135, 111 